Supporting information for:

\title{
Precisely Defined Amphiphilic Graft Copolymers
}

Erik B. Berda, Rachel E. Lande, and Kenneth B. Wagener*

The George and Josephine Butler Polymer Research Laboratory

Department of Chemistry

University of Florida

Gainesville, FL 32611-7200

* Corresponding author wagener@ chem.ufl.edu

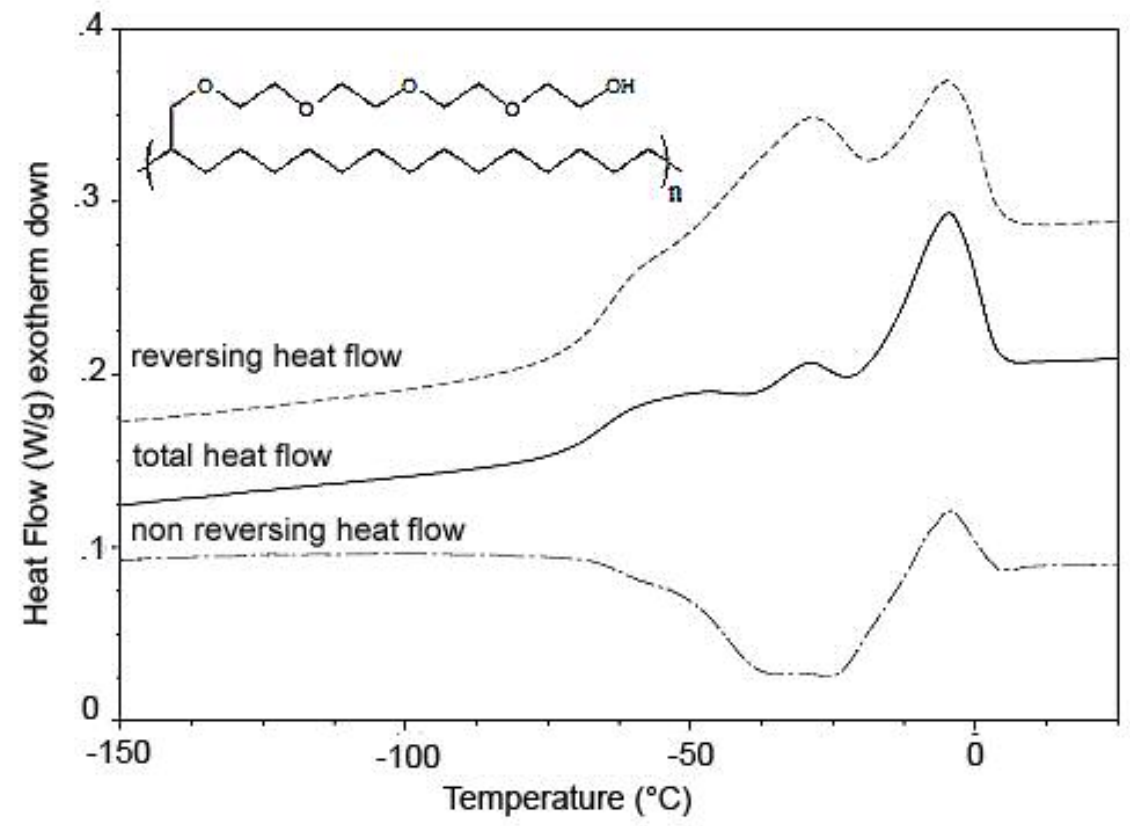

Figure S.1.: Modulated DSC of TEGOH15 (5b). 


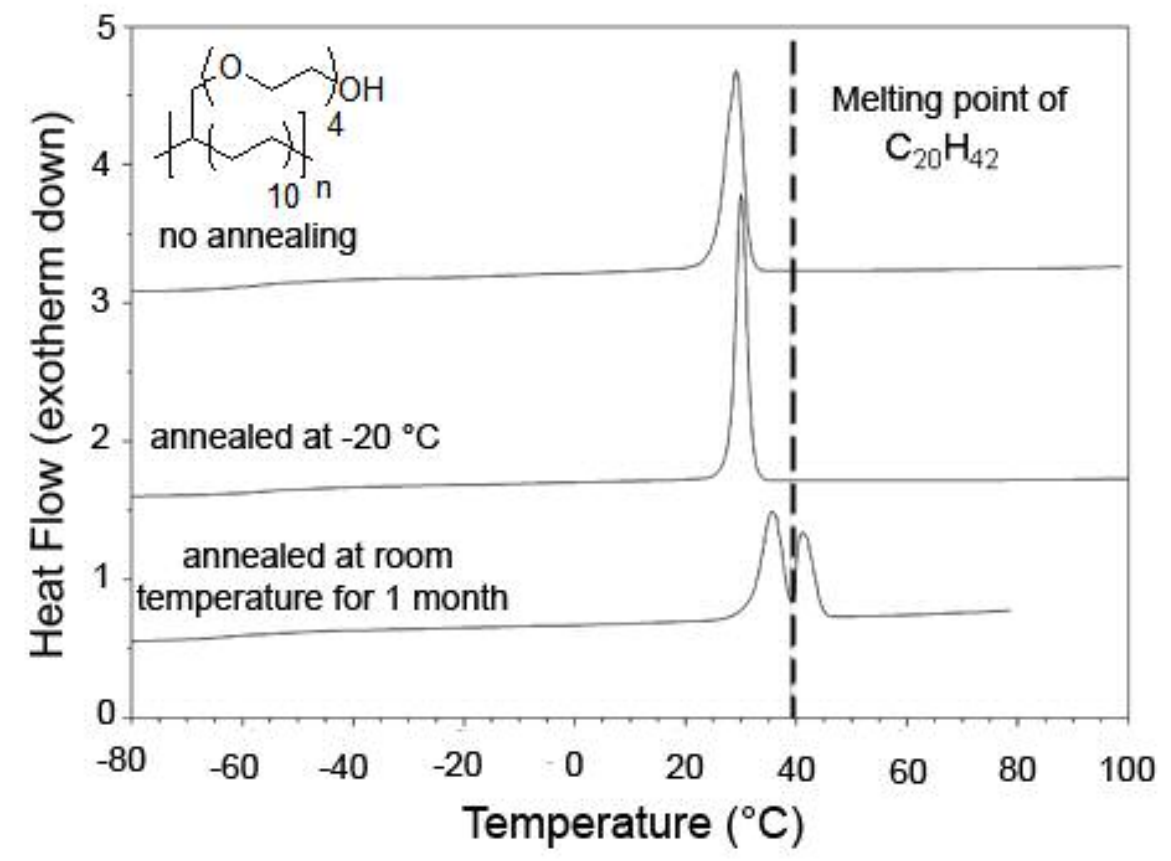

Figure S.2.: Annealing TEGOH21 (5c).

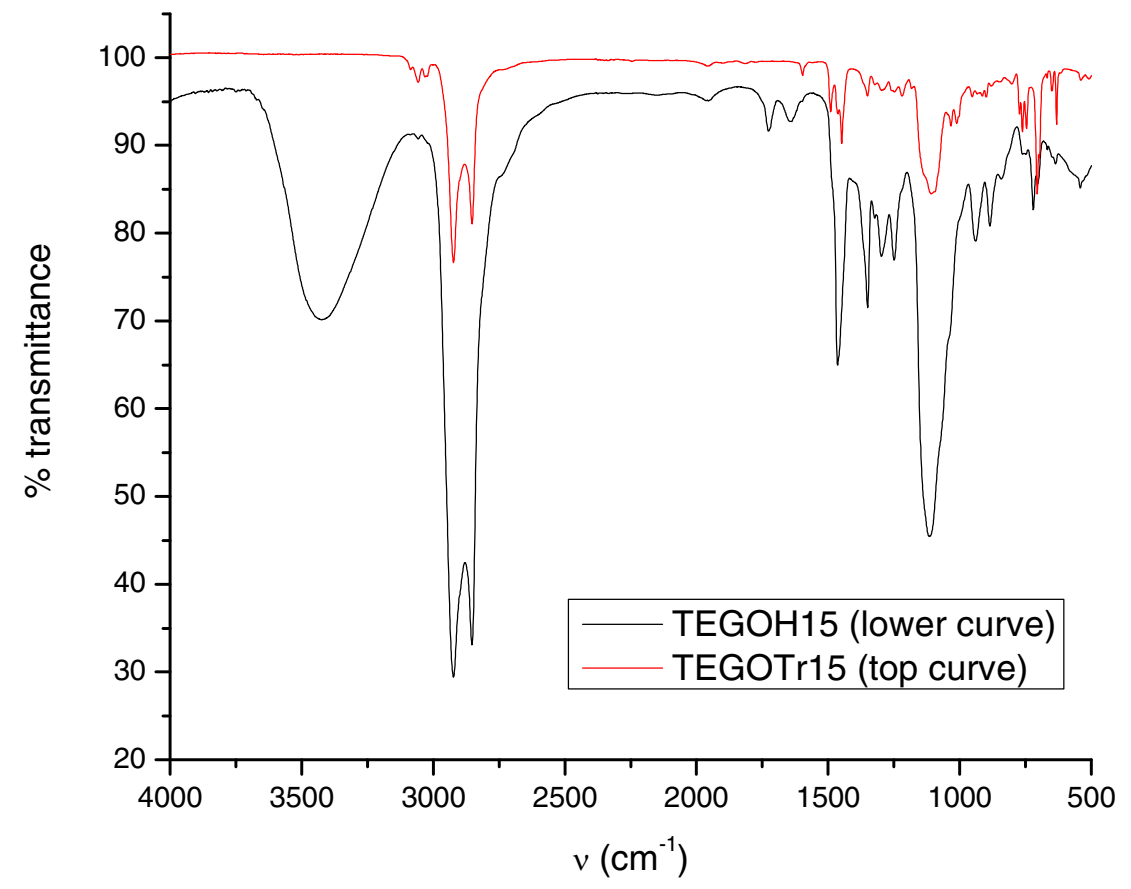

Figure S.3.: IR spectrum of TEGOH15 (5b) and TEGOTr15 (4b) (arbitrarily chosen as examples) showing clear hydrogen bonding stretch at $\sim 3500 \mathrm{~cm}^{-1}$ in $\mathbf{5 b}$ but absent in $\mathbf{4 b}$. 


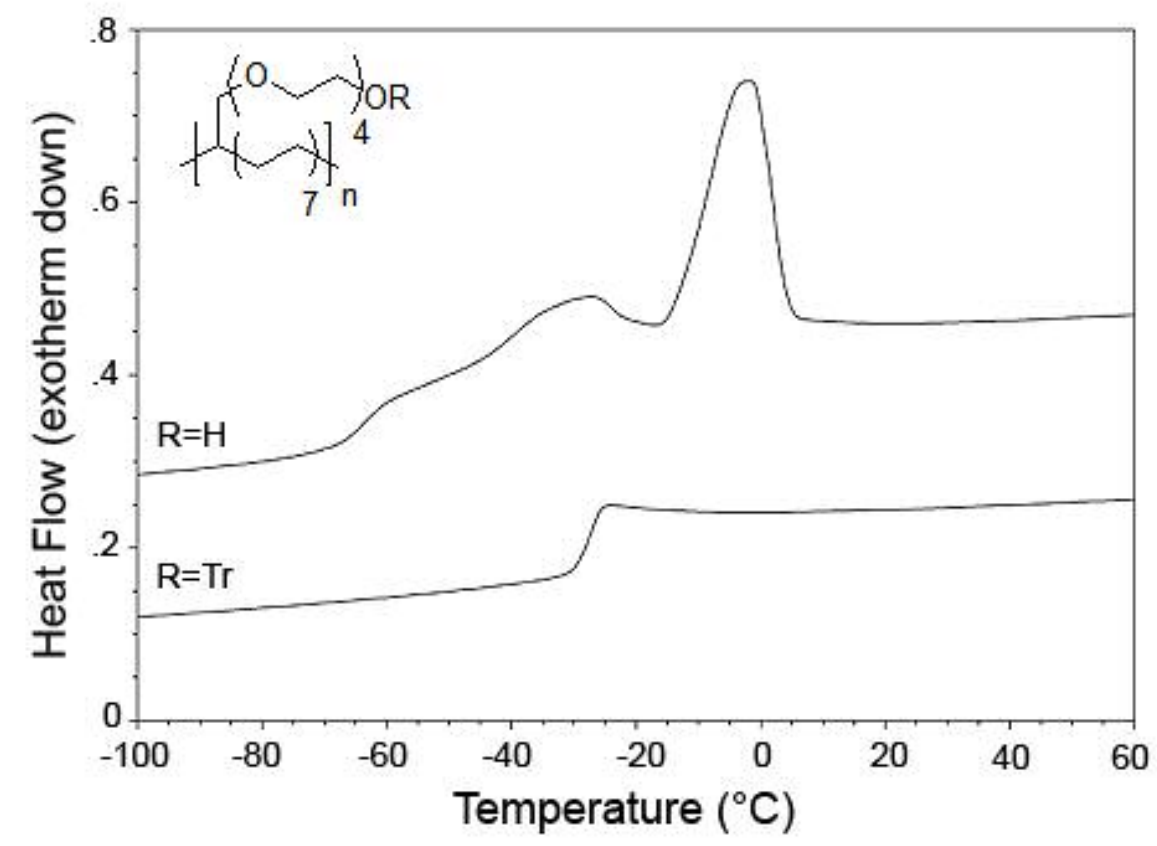

Figure S.4.: DSC comparison of TEGOTr15 (4b) and TEGOH15 (5b).

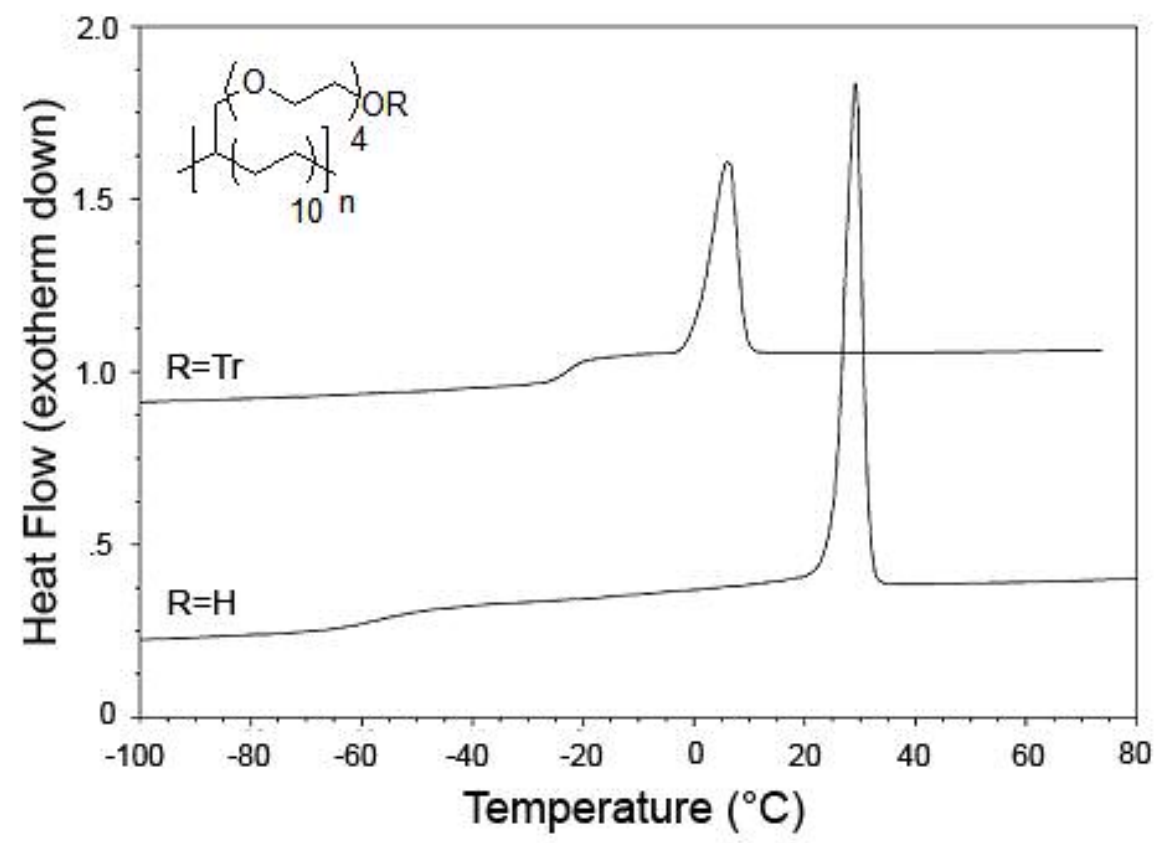

Figure S.5.: DSC comparison of TEGOTr21 (4c) and TEGOH21 (5c), second heating trace. 